\title{
Waste Generation Rate and Composition Analysis of Solid Waste in Gujranwala City Pakistan
}

Hassan Ilyas ${ }^{2 *}$, Shazia Ilyas ${ }^{2}$, Sajid Rashid Ahmad ${ }^{1}$ and Muhammad Nawaz Ch $^{\mathbf{1}}$

${ }^{1}$ College of Earth and Environmental Sciences (CEES), University of the Punjab, Lahore, Pakistan

${ }^{2}$ Urban Sector Planning \& Management Services Unit Pvt. Ltd. (The Urban Unit), 503-Shaheen Complex, Egerton Road, Lahore, Pakistan

\begin{abstract}
In developing countries like Pakistan, the amount of solid waste is increasing due to rapid urbanization and economic growth. Limited financial resources and lack of data availability about the amount and composition of the solid waste are posing difficulties to regulatory bodies towards proper planning of solid waste management systems in big cities. Also, solid waste generation and characterization are the essential parameters that affect the environmental sustainability. The aim of this study is to document the information on waste quantity being produced and its composition in Gujranwala city of the Pakistan. Results of this study can help the government to develop a sound waste management system for such expanding cities in the country. Average waste generation rate of four groups of residential areas (rural, low, middle and high income) were calculated and found to be ranged from 0.33 kilograms per capita per day $(\mathrm{kg} / \mathrm{c} / \mathrm{d})$ for rural or low income areas to $0.46 \mathrm{~kg} / \mathrm{c} / \mathrm{d}$ for high income areas. Waste comprises of 15 categories, with kitchen waste $43-68 \%$ as the largest component of the waste.
\end{abstract}

Keywords: Gujranwala; Solid waste; Composition analysis; Municipal waste; Generation rate

\section{Introduction}

One of the key practices for resource conservation and environmental protection is the proper waste management [1]. In waste management, municipal solid waste management (MSWM) is one of the important element of environment which is highly neglected in most of the under developed and developing countries [2]. In developed countries collection of MSW is equal to generation amount, however in developing countries like Pakistan, India, Bangladesh etc., the scenario is very different and management of MSW consists of primary and secondary collection and open dumping [3-6]. In 1996, population of Pakistan was 160 million with $35 \%$ population living in urban areas and the total waste generation rate in urban areas of Pakistan was 55,000 tons per day [7]. By the end of 2014, waste generation in Pakistan was as high as 71,000 tons/day [8]. However, the current population has increased to 196 million people, which is pushing the boundaries of cities and indicates higher waste generation amount. This increasing amount of solid waste is one of the most daunting challenges to regulatory authorities to maintain clean cities.

Economic growth, urbanization, demographic growth and changing life styles are the key reasons behind increase in MSW generation in Pakistan [9]. Increased solid waste amount pose difficulty in efficient waste management process (transportation, storage and disposal) [10]. Worldwide quantity and composition of solid waste varies with region/state, climate and socio-economic conditions [1114]. In most of the Pakistani cities only $60 \%$ of the waste is collected and $90 \%$ of the collected waste ends up in open dumping [5]. However, for cities to be relatively clean more than $75 \%$ of the waste must be collected. The MSW generation rate in Data Ganj Bakhash Town of Lahore City of Pakistan was estimated at $0.84 \mathrm{~kg} / \mathrm{capita} /$ day with total 1369.8 tons per day of waste with $67.02 \%$ organic waste [5]. Lack of reliable data, poor institutional arrangements, non-compliance of laws, limited resources (finance and equipment), lack of trained manpower are the major constrains for proper management of MSW. In Pakistan during the last decade due to migration of people from rural to urban areas the population rate in cities has increased from 3.7-7.4\%.
For the design and operation of effective solid waste management system, information on the sources, generation rates, solid waste characteristics and composition is required. Current study was aimed to collect this basic information about waste in Gujranwala city of Pakistan. This is part of three seasonal waste amount and composition survey study of Gujranwala city; one part of this study has been published previously [15]. At the present, there is no engineering designed landfill facility in Gujranwala city. There is no comprehensive waste management system or strategy in the city and the Waste is dumped close to living areas and is posing challenges to public health, surface and ground water quality and sustainable development. Present study aims to determine qualitative and quantitative characteristics of the municipal solid waste from Gujranwala city.

\section{Material and Methods}

\section{Characteristics of study area}

Gujranwala is one of the populated city of Punjab province of Pakistan and is located at $32.1^{\circ}$ North, $74.9^{\circ}$ East. Gujranwala is 226 meters above sea-level. Gujranwala city is the fifth biggest city of Pakistan and comprised of seven towns. The total population of the city in 2007 was $1,415,711$ [16] and population in 2017 is estimated to be $2,027,001$ [17]. Area of the city is about $238.1 \mathrm{~km}^{2}$.

\section{Sampling design}

For this study waste samples of the Gujranwala city were collected from including both the city and peri-urban areas. The purpose of this

*Corresponding author: llyas $\mathrm{H}$, Urban Sector Planning \& Management Services Unit Pvt. Ltd. (The Urban Unit), 503-Shaheen Complex, Egerton Road, Lahore, 54000, Pakistan, Tel: + 92331 6671689; E-mail: Hassanilyas.env@gmail.com

Received Augus 28, 2017; Accepted September 07, 2017; Published September 14,2017

Citation: Ilyas H, Ilyas S, Ahmad SR, Nawaz MCH (2017) Waste Generation Rate and Composition Analysis of Solid Waste in Gujranwala City Pakistan. Int J Waste Resour 7: 297. doi: 10.4172/2252-5211.1000297

Copyright: (c) 2017 llyas $\mathrm{H}$, et al. This is an open-access article distributed unde the terms of the Creative Commons Attribution License, which permits unrestricted use, distribution, and reproduction in any medium, provided the original author and source are credited. 
sampling survey was to quantify amount of waste generated and to know about composition of the waste, which later will help to suggest waste management strategy. Ten sources of waste considered for this study are listed in Table 1 . House hold sources were categorized into high, medium and low income level areas for stratified sampling. 97 sampling points in total for each source type were selected (Table 1), and waste amount to discharge ratio was calculated. Sampling was performed for 8 days (13th of October to 20th of October 2014) which resulted in a total of 776 waste samples from all sources considered for this study. The information about households, number of individuals per household, number of employees, floor area, and total area was collected from survey.

\section{Waste quantity}

For determining waste generation rate, we utilized output method [18], also known as load count analysis and this method involves less efforts and finance as compared to Input method. Samples from each source were collected in plastic bags assigned with source code except the markets, where samples were collected in specially assigned vehicles. Waste generation rate from each source was calculated by weighing the waste quantity. Sampling was carried out for 8 days but here in this paper we only reported data of 7 days. Results of first day are not included due to accumulation of waste from the previous day. To calculate waste generation rate average household size used was 7.76 people.

\section{Composition of waste}

Physical composition: Physical and chemical composition of solid waste plays an important role in selection of appropriate waste management strategy [19]. For composition analysis of waste a controlled designated disposal site away from winds was used where unloading and weighing of collected samples was done. For composition analysis of the municipal solid waste standard method ASTM-D5231-92 was used [20]. This method requires a representative sample of 100-200 kg from a week-day collection route in residential areas. Reduction method was used for large waste generation sources to get sample of approximately $200 \mathrm{~kg}$ and for samples less than $200 \mathrm{~kg}$ direct segregation was used.

To prepare homogeneous and representative sample, the waste sample was mixed thoroughly and divided into 4 piles of same volume followed by removal of two parts of waste at diagonal opposite ends and mixing the remaining amount. Once the representative sample was prepared it was loaded in plastic bucket of 30 liters capacity and dropped down at ground three times from a height of $30 \mathrm{~cm}$. Later the volume of the waste and weight was measured. Apparent specific gravity was calculated by dividing the weight of waste in bucket to volume of waste.

The composition ratio of each waste in wet base, $\mathrm{Xi}$ (\%), was calculated as follows.

$$
\mathrm{Xi}=\frac{\text { Weight of each weight composition }(\mathrm{kg})}{\text { Total amount of each waste composition }(\mathrm{kg})} \times 100
$$

(equation 1)

On the basis of physical composition, the samples were divided into 15 physical components as listed in Table 2.

Chemical composition of waste: Chemical composition analysis carried out for this study involved analysis of moisture content (MC) of waste, carbon and nitrogen analysis and three component analysis. These analyses were performed in laboratory at Pakistan Council for Scientific and Industrial Research (PCSIR), Lahore.

For MC analysis, at least $1 \mathrm{~kg}$ of waste of each composition was

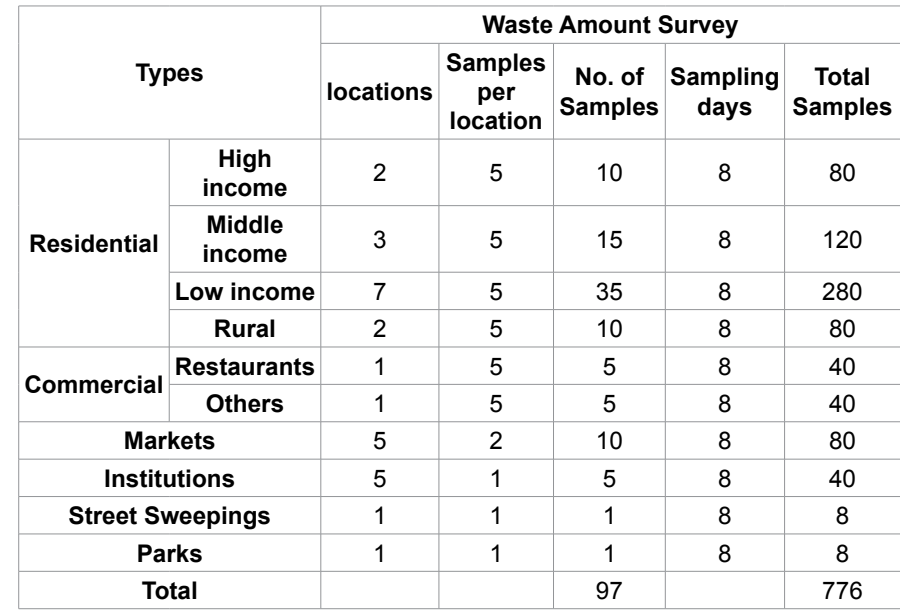

Table 1: Sampling design for waste generation sources.

\begin{tabular}{|c|c|c|c|c|c|}
\hline \multirow{3}{*}{$\begin{array}{l}\text { Sr. } \\
\text { No }\end{array}$} & \multirow{3}{*}{ Item } & $\begin{array}{c}\text { High } \\
\text { income }\end{array}$ & $\begin{array}{l}\text { Middle } \\
\text { income }\end{array}$ & $\begin{array}{c}\text { Low } \\
\text { income }\end{array}$ & $\begin{array}{l}\text { Rural } \\
\text { areas }\end{array}$ \\
\hline & & Average & Average & Average & Average \\
\hline & & $(\%)$ & $(\%)$ & $(\%)$ & $(\%)$ \\
\hline & Kitchen waste & 66.32 & 55.24 & 67.6 & 42.9 \\
\hline & $\begin{array}{c}\text { Paper } \\
\text { (recyclable) }\end{array}$ & 7.36 & 5.25 & 3.2 & 2.9 \\
\hline & $\begin{array}{c}\text { Paper (Tetra } \\
\text { Pak and other } \\
\text { paper) }\end{array}$ & 0.53 & 1.90 & 0.5 & 0.2 \\
\hline & Textile & 5.40 & 5.74 & 4.9 & 3.8 \\
\hline & $\begin{array}{l}\text { Grass and } \\
\text { wood }\end{array}$ & 0.35 & 0.66 & 0.5 & 9.3 \\
\hline & $\begin{array}{c}\text { Plastic } \\
\text { (recyclable) }\end{array}$ & 1.79 & 1.39 & 0.8 & 0.8 \\
\hline & $\begin{array}{l}\text { Plastic (non- } \\
\text { recyclable) }\end{array}$ & 9.82 & 8.39 & 10.9 & 6.6 \\
\hline & $\begin{array}{l}\text { Leather and } \\
\text { rubber }\end{array}$ & 0.63 & 1.51 & 1.8 & 0.5 \\
\hline & $\begin{array}{c}\text { Metal } \\
\text { (recyclable) }\end{array}$ & 0.23 & 0.55 & 0.1 & 0.4 \\
\hline & $\begin{array}{l}\text { Metal (non- } \\
\text { recyclable) }\end{array}$ & 0.00 & 0.00 & 0.0 & 0.0 \\
\hline & $\begin{array}{c}\text { Bottle } \\
\text { and glass } \\
\text { (recyclable) }\end{array}$ & 0.27 & 0.95 & 1.5 & 0.0 \\
\hline & $\begin{array}{l}\text { Bottle and } \\
\text { glass (non- } \\
\text { recyclable) }\end{array}$ & 1.03 & 0.46 & 0.8 & 0.0 \\
\hline & $\begin{array}{l}\text { Ceramic, stone } \\
\text { and soil etc. }\end{array}$ & 0.49 & 8.30 & 2.5 & 27.2 \\
\hline & $\begin{array}{c}\text { Domestic } \\
\text { hazardous } \\
\text { wastes }\end{array}$ & 0.51 & 0.98 & 0.8 & 0.5 \\
\hline & $\begin{array}{l}\text { Miscellaneous } \\
\text { (Diapers etc.) }\end{array}$ & 5.27 & 8.67 & 4.2 & 4.8 \\
\hline & Total & 100.00 & 100.00 & 100.0 & 100.0 \\
\hline
\end{tabular}

Table 2: Average waste composition of residential areas.

used. First the samples were sealed in aplastic bag to avoid loss in MC and then kept in oven/incubator for 4-5 days at a temperature range of 90-100 ${ }^{\circ} \mathrm{C}[21]$. Then MC was calculated as follows: $\mathrm{MC}(\%)=\frac{\text { Weight of sample before drying }(\mathrm{kg}) \text {-Weight of sample after drying }(\mathrm{kg})}{\text { Weight of sample before drying }(\mathrm{kg})} \times 100$ equation $(2)$

Total Kjeldahl Nitrogen Method using mercuric oxide ormetallic mercury $\mathrm{HgO}$ or $\mathrm{Hg}$ as a catalyst was used to analyse Nitrogen content 
of waste samples [22].

- Carbon and Nitrogen concentration was measured for waste type $1,2,3$ and 5 .

- Three component analysis was performed for waste types 1 to 15 .

- Moisture content of combustible waste was measured for waste type $1,2,3,4,5$ and 8 .

For three component analysis three contents moisture, ash and combustible were analyzed for waste types 1 to 15 . For this analysis $6 \mathrm{~g}$ waste was measured by $100 \mathrm{ml}$ crucible furnace. Samples were heated in an electric furnace at 800 degree Celsius for about 3 hours and cooled down and dried at $105^{\circ} \mathrm{C}$ temperature. Desiccators were used for cooling purpose and samples were kept in desiccator for 20-30 min and weighed. Then combustible (V) and ash component (A) were determined.

$$
\begin{aligned}
V(\%)= & \frac{\text { Weight of sample }(g) \text {-Weight of sample after heating }(g)}{\text { Weight of sample }(g)} \times 100 \\
A(\%) & =\frac{\text { Weight of sample after heating }(g)}{\text { Weight of sample }(g)} \times 100
\end{aligned}
$$

(equation 3)

(equation 4)

\section{Results and Discussion}

The results of this study reveal the composition of waste from Gujranwala city which is a mixture of different components. The significant portion of the waste is organic (more than $80 \%$ ) waste which is compostable. Higher contents of organic waste show good prospect of composting technique and frequent collection and removal of waste from point of generation.

\section{Waste amount}

The average household size of high, middle, low and rural areas was found to be 7.76 people. Average waste generation rate of four groups of residential areas ranges from 0.33 kilograms per capita per day $(\mathrm{kg} / \mathrm{c} / \mathrm{d})$ to $0.46 \mathrm{~kg} / \mathrm{c} / \mathrm{d}$. Figure 1a is similar to the results reported in previous study for winter season [15]. Areas with high income produce more waste as compared to low income areas or rural areas, this shows that living standard determines the amount of waste generated.

In Figure $1 \mathrm{~b}$ average waste generation from sources other than residential areas is shown. Due to lack of information about number of persons producing waste in these areas we have given the average weight of waste generated during 7 days of sampling. Among commercial sources, restaurants are higher producer of waste with quantity of 10.98 $\mathrm{kg} /$ day following public parks with $9 \mathrm{~kg}$ /day waste quantity. Street sweepings represents least contribution of about $1.8 \mathrm{~kg} /$ day in waste generation. Shops produce $2.07 \mathrm{~kg} /$ day of the waste and institutions $4.66 \mathrm{~kg} /$ day respectively. Similarly, waste amount survey has been conducted in fruit and vegetable markets of Gujranwala. There are 2 wholesale fruit and vegetables markets where Gujranwala municipal committee has placed a container of $5 \mathrm{~m}^{3}$. Other markets, which are basically unofficial sale points of fruits and vegetable, are scattered all over the city. 8 major points were selected for sample collection in the unofficial sale points.

Specific gravity for each waste category was calculated and is given in Figure 2. Specific gravity of waste from four residential areas ranges from $275 \mathrm{~kg} / \mathrm{m}^{3}$ for high income areas to $285 \mathrm{~kg} / \mathrm{m}^{3}$ for low income areas, however commercial waste from restaurants have highest value of apparent specific gravity of about $527 \mathrm{~kg} / \mathrm{m}^{3}$.

\section{Physical composition}

Physical composition of waste from four residential area categories for 15 items is given in Table 2. As can be seen from, overall the household waste comprises of highest amount of kitchen waste which is $43-68 \%$ of total waste, followed by paper (3-7\%) and plastic waste (08$11 \%)$. Metals are hardly found in household waste because most of the metal is recycled or segregated at household level [9]. The composition of waste in rural areas is different than urban areas (high, medium and low income) and comprises of $43 \%$ kitchen waste, $10 \%$ grass and wood, $27 \%$ stones and soil. Recyclable plastic and glass is absent in rural waste which is directly linked with socio-economic condition of the area (Table 2). Textile waste and non-recyclable plastic is also found in large amount in residential waste.

For the sources, other than residential areas results of physical composition of waste are given in Figure 3. It can be seen that waste generated from restaurants (Figure 3a) is also rich in kitchen waste up to $77 \%$ (comprises of fresh vegetable and fruit scraps and peelings) the rest of the waste is mainly paper (14\%) and plastic (7\%). These stand as prominent components owing to the sector's utilization and discarding of paper from everyday use, receipts, shopping bags and other plastic packaged products that fall in the category that cannot be recycled. Waste from commercial sources (commercial zones with shopping centers and markets at its heart) is mainly comprised of paper (52\%) and non-recyclable plastic (25\%) (Figure 3b). The major activity for this category is buying and selling (that greatly involves paper packaging as well as plastic bags) which explains the exorbitant amounts of recyclable papers and non-recyclable plastics in the waste stream. Waste produced from commercial markets is $49 \%$ kitchen waste and $27 \%$ grass and wood (Figure 3c). While looking at this representation of various components on percent proportion the component that catches the eye is presence of grass and wood. It is worth mentioning here that it is a common practice to pack fruits and vegetables in wooden crates with dried straw, old newspapers and other discarded paper serving as cushioning to this merchandise. This is quite prevalent in whole sale markets dealing in farm fresh fruits and vegetables. The wooden crates

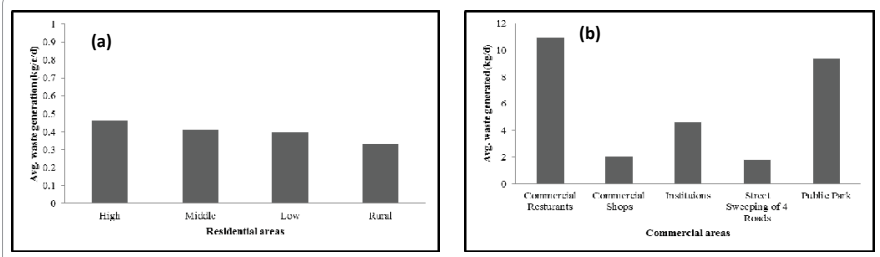

Figure 1: Amount of waste generated from (a) residential sources in kg/capita/ day; (b) non-residential sources $\mathrm{kg} /$ day.

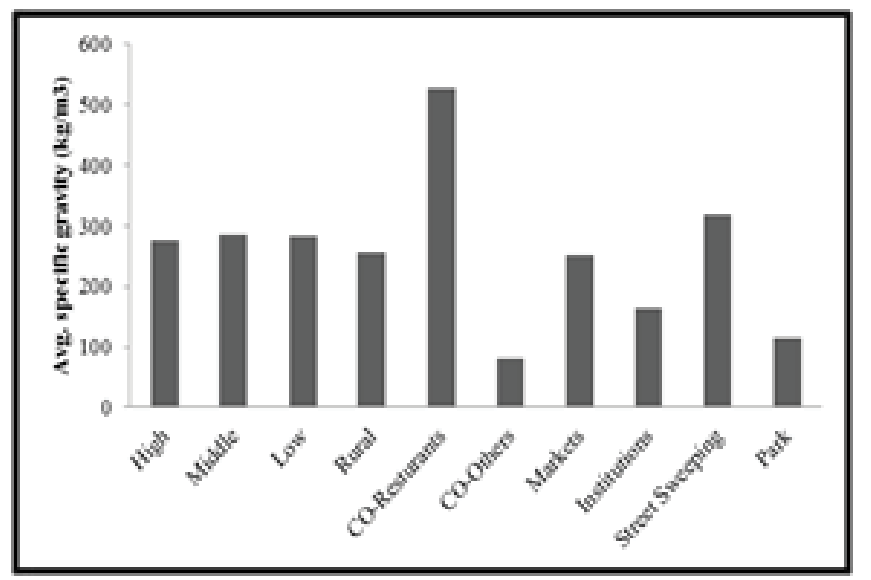

Figure 2: Average specific gravity of waste $\left(\mathrm{kg} / \mathrm{m}^{3}\right)$ 

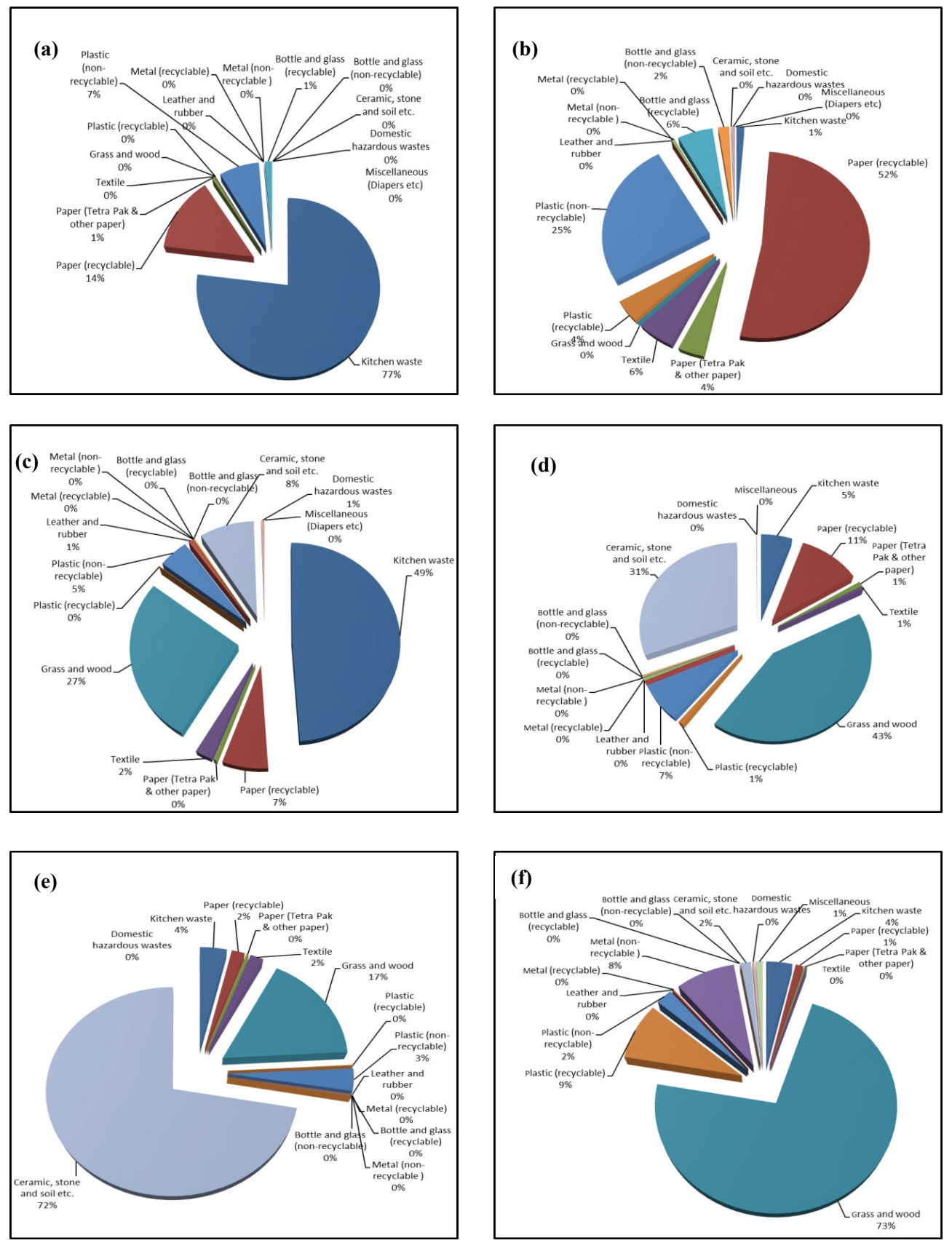

Figure 3: Physical composition of waste generated from different sources (a) commercial restaurants; (b) commercial sources; (c) market sources; (d) institutions; (e) street sweeping; (f) park areas.

along with the cushioning material are discarded daily in abundance after the products are extracted and sold. In addition, rotten fruits and vegetables are also sent to the waste bins that are often accompanied by soil and dirt. This is the reason behind the present composition, with kitchen waste (here may be termed as vegetable or green waste) approximately $50 \%$ of the total waste.

Institutional (institutions and offices) waste contains $43 \%$ grass and wood, and $31 \%$ ceramic, soil and stones, and $11 \%$ paper waste (Figure $3 \mathrm{~d}$ ). In street sweeping $72 \%$ ceramic, stone and soil, $17 \%$ grass and wood (Figure 3e). This sort of composition that is dominated by leafy, woody and earthy components arises due to the fact that all the sampled sites have large play areas and plantation covered grounds that add large volumes of grass clipping and green pruning. Moreover, the fallen-off leaves due to autumn season added enormously to the yard waste. Recyclable paper is a predominant waste from schools, colleges and offices and so, there is no astonishment associated to its percentage that the statistics reveal. Waste from street sweeping contained the highest proportion of stones and soil. Composition analysis indicates about $72 \%$ of the waste comprised of inert category. Wood and grass contributed $17 \%$ to the total percentage composition. Park waste is mainly composed of grass and wood up to $73 \%$ (Figure $3 \mathrm{f}$ ). This includes 
grass and plant pruning and loose tree leaves that are shed due to the autumn season. Recyclable plastic represents $9 \%$ of the total park waste which is result of recreational activities leaving behind beverage bottles. Fruit peeling left by park visitors and food scraps as a consequence of snack vendors and food stalls contribute $4 \%$ kitchen waste to the total percentage composition.

\section{Chemical composition}

The chemical composition of the waste is determined in terms of moisture content, $\mathrm{C}: \mathrm{N}$ ratio and three component analysis. Average values for moisture content of the residential areas are given in Figure 4a. A total of 36 samples ( 9 samples of each of 4 categories) were used to carry out moisture content analysis and found to be $54.8 \%$. For waste of high income areas $\mathrm{MC}$ of $59.4 \%$, middle income regions $46.5 \%$, low income $54.4 \%$ and market areas $58.2 \%$ of MC was observed.

The average value of $\mathrm{C}: \mathrm{N}$ ratio for all samples was found to be 109.55. C:N ratio for waste of high income regions was 113.31, middle income 131.13, low income region 113.13 and 80.65 for market waste (Figure 4b).

For the three-component analysis; moisture content, ash content and combustible content was analyzed (Figure 5). The average of moisture content analysis performed in the three-component analysis for 36 samples turned out to be $66.6 \%$. Waste of high income areas have $70.3 \%$ moisture content, middle income areas $63.2 \%$, low income areas $65.5 \%$ and market areas have $67.4 \%$ of the moisture content.

The average value of combustible content is found to be $86.2 \%$, with highest value for high income areas (92.4\%). In middle and low income areas, combustible content is found to be similar $86.6 \%$ and $87.6 \%$ respectively. Lowest combustible content is found in market areas waste (78.0\%). Similarly, the average ash content for these samples is $13.8 \%$. Highest ash content is observed for waste from market areas (22.0\%) and lowest for high income residential areas (7.6\%). Ash content of waste from middle income and low income regions is in the range of $12.4-13.4 \%$.

\section{Conclusion}

Waste amount and composition survey of Gujranwala city revealed some interesting figures. Some of the datasets are discussed here as results. The average size of the household in Gujranwala city is 7.7. Waste generation rate ranges from $0.46 \mathrm{~kg} / \mathrm{c} / \mathrm{d}$ for high income areas to $0.33 \mathrm{~kg} / \mathrm{c} / \mathrm{d}$ for rural areas. Similarly, waste generation rate for commercial set ups is $10.98 \mathrm{~kg} /$ day, it is $2.07 \mathrm{~kg} /$ day for shops, $4.66 \mathrm{~kg} /$ day for institutions, $1.8 \mathrm{~kg} /$ day from street sweeping and as high has 9.4 $\mathrm{kg} /$ day for parks. Analysis shows that specific gravity for waste from high income is $275 \mathrm{~kg} / \mathrm{m}^{3}, 285 \mathrm{~kg} / \mathrm{m}^{3}$ and $283 \mathrm{~kg} / \mathrm{m}^{3}$ for middle and low income, whereas $256 \mathrm{~kg} / \mathrm{m}^{3}$ for waste from rural areas. Average

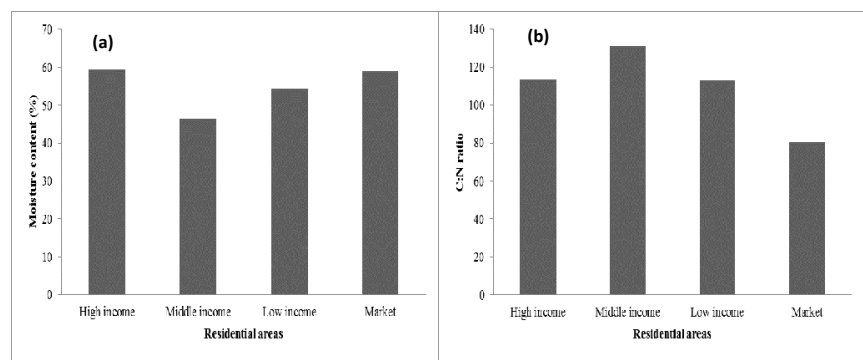

Figure 4: Chemical composition analysis of the waste from residential areas (a) moisture content; (b) carbon/nitrogen ratio $(\mathrm{C}: \mathrm{N})$ of waste.

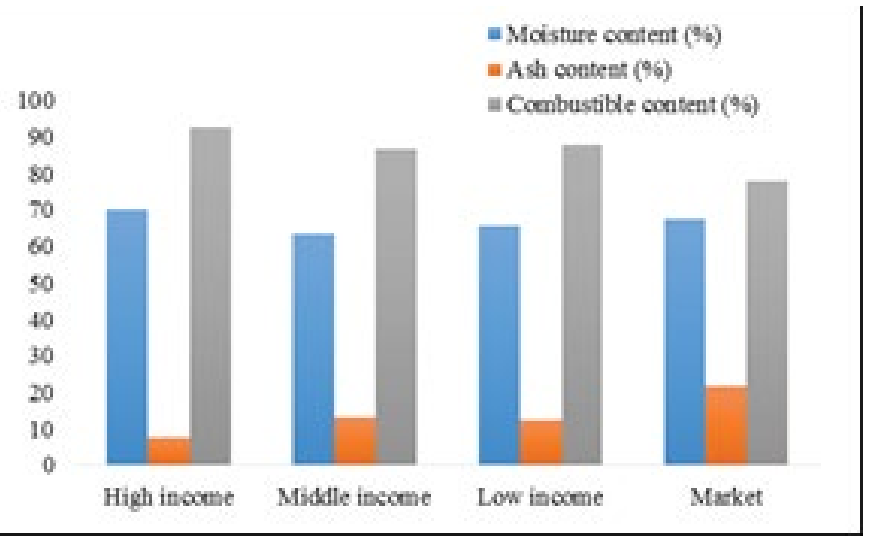

Figure 5: Three component analysis of solid waste.

moisture content is found to be $59.4 \%, \mathrm{C}: \mathrm{N}$ ratio 11.2 , combustible content $86 \%$ and ash content $13.8 \%$.

\section{References}

1. Sandulescu (2004) The contribution of waste management to the reduction of greenhouse gas emissions with applications in the city of Bucharest. Waste Manag Res 22: 413-426.

2. Murtaza MG, Rahman MA (2000) Solid waste management in Khulana city and a case study of a CBO: Amader Paribartan. In: Community Based Solid Waste Management: The Asian Experience. Waste Concern, Dhaka, Bangladesh. pp: 151-168.

3. Shimura S, Yokota I, Nitta Y (2001) Research for MSW flow analysis in developing nations. J Mater Cycles Waste Manag 3: 48-59.

4. Sharholy M, Ahmad K, Vaishya RC, Gupta RD (2007) Municipal solid waste characteristics and management in Allahabad, India. Waste Manag 27: 490496.

5. Batool SA, Chaudhry MN (2009) Municipal solid waste management in Lahore City District, Pakistan. Waste Manag 29: 1971-1981.

6. Ali M, Wang W, Chaudhry N (2016) Management of wastes from hospitals: A case study in Pakistan. Waste Manag Res 34: 87-90.

7. Japan International Cooperation Agency (JICA), Pakistan Environmental Protection Agency (Pak-EPA) (2005) Guidelines for solid waste management.

8. Masood M, Barlow CY, Wilson DC (2014) An assessment of the current municipal solid waste management system in Lahore, Pakistan. Waste Manag Res 32: 834-847.

9. Batool SA, Chaudhry N, Majeed K (2008) Economic potential of recycling business in Lahore, Pakistan. Waste Manag 28: 294-298.

10. Ozcan HK, Guvenc SY, Guvenc L, Demir G (2016) Municipal solid waste characterization according to different income levels: A case study. Sustainability 8: $1044-1049$

11. Liamsanguan C, Gheewala SH (2008) LCA: A decision support tool for environmental assessment of MSW management systems. J Environ Manage 87: $132-138$.

12. Chen CC (2010) A performance evaluation of MSW management practice in Taiwan. Resource Conservation and Recycling 54: 1353-1361.

13. Trulli E, Torretta V, Raboni M, Masi S. (2013) Incineration of pre-treated municipal solid waste (MSW) for energy co-generation in a non-densely populated area. Sustainability 5: 5333-5346.

14. Ciuta S, Apostol T, Rusu V (2015) Urban and rural MSW stream characterization for separate collection improvement. Sustainability 7: 916-931.

15. Nadeem K, Farhan K, llyas H (2016) Waste amount survey and physiochemical analysis of municipal solid waste generated in Gujranwala-Pakistan. Inte J Waste Resour 6: 196.

16. KOICA (2007) Report 2 of KOICA-World Bank joint study on Punjab solid waste management in Pakistan. 
Citation: Ilyas H, llyas S, Ahmad SR, Nawaz MCH (2017) Waste Generation Rate and Composition Analysis of Solid Waste in Gujranwala City Pakistan. Int J Waste Resour 7: 297. doi: 10.4172/2252-5211.1000297

17. Pakistan Bureau of Statistics (2017) Provisional summary results of $6^{\text {th }}$ population and housing census-2017.

18. Worrell WA, Vesilind AP (2011). Solid waste engineering. Cengage Learning, Stamford, USA. pp. 33-38.

19. Khan MZA, Burney FA (1989) Forecasting solid waste composition - An important consideration in resource recovery and recycling. Resour Conserv Recy 3: 1-17.
20. ASTM D5231 - 92 (2003) Standard test method for determination of the composition of unprocessed municipal solid waste. ASTM International, West Conshohocken, PA. p. 6.

21. ASTM E790-08 (2008) Standard test method for residual moisture in a refusederived fuel analysis sample, ASTM International, West Conshohocken, PA.

22. Bremner JM, Mulvaney CS (1982) Methods of soil analysis, Part 2. In: AL Page $\mathrm{RH}$ Miller, DR Keeney (eds). Chemical and Microbiological Properties (2nd edn.). American Society of Agronomy, Madison, WI. pp: 595-624. 